\title{
Educação musical na educação do campo: metodologias alternativas em uma abordagem contemporânea
}

\section{Musical education in field education: alternative methodologies in a contemporary approach}

\author{
Waldir Pereira da Silva, Aparecida de Jesus Soares Pereira \\ Universidade Federal do Tocantins
}

\begin{abstract}
Resumo
$\mathrm{O}$ presente trabalho aborda aspectos relacionados às metodologias alternativas utilizadas na educação musical dos alunos do Curso de Licenciatura em Educação do Campo: Códigos e Linguagens - Artes Visuais e Música da Universidade Federal do Tocantins - UFT/BR, Campus de Arraias, sendo as disciplinas ministradas em regime de alternância pedagógica. A habilitação em música propõe formar professores para atuarem nas séries finais do Ensino Fundamental e Ensino Médio nas escolas do e no campo em prol de uma educação campesina de qualidade. A metodologia desenvolvida baseia-se na percussão corporal a partir das ideias de Émile-Jaques Dalcroze aplicadas a uma realidade encontrada.

Palavras chave: Educação do campo, Educação musical, Metodologia.
\end{abstract}

\begin{abstract}
The present work addresses aspects related to the alternative methodologies used in the musical education of the students of the Undergraduate in Field Education: Codes and Languages - Visual Arts and Music of the Federal University of Tocantins - UFT / BR, Arraias Campus, being the disciplines taught In a system of pedagogical alternation. The qualification in music proposes to train teachers to act in the final series of Elementary and High School in the schools of the and in the field in favor of a peasant education of quality. The developed methodology is based on the body percussion from the ideas of Émile-JaquesDalcroze applied to a reality found.
\end{abstract}

Keywords: Field education, Music education, Methodology.

\section{Educação do e no campo}

Sendo o Brasil um país de dimensões continentais, os habitantes do campo estiveram, de certa forma, relegados à marginalidade, no que diz respeito à construção de projetos educacionais que fossem condizentes com sua realidade, produzindo no país o êxodo rural.

Sobre a realidade de abandono da educação no campo, um dos motivos do êxodo rural, Silva (2012, p.170) argumenta que tal fato se deve a "insuficiência de escolas, condições precárias de infra-estrutura, professores sem qualificação, currículos inadequados, são representações que denunciam a presença de uma escola e uma educação divorciada dos interesses e das necessidades da população rural".

A atuação de grupos sociais, como o Movimento dos Trabalhadores Rurais Sem Terra (MST), apoiados pelas universidades tem conseguido avanços no sentido de mudar a realidade educacional campesina, mas ainda distante do que se espera, devido à falta de maior apoio dos órgãos governamentais quanto a escassez de políticas públicas para uma educação do e no campo.

De acordó com Caldart (2009, p.39) "A Educação do campo nasceu como crítica à realidade da educação brasileira, particularmente à situação educacional do povo brasileiro que trabalha e vive no/do campo".

Sendo assim, os movimentos sociais discutiram e cobraram do governo políticas específicas para atender ao segmento do campo e sua realidade

A Lei ${ }^{\circ}$ 9.394, vigente desde 1996, estabelece a Lei de Diretrizes e Bases da Educação Nacional (LDBEN) e, em seu artigo 28 se refere as escolas do campo:

Art. $28^{\circ}$. Na oferta de educação básica para a população rural, os sistemas de ensino promoverão as adaptações necessárias à sua adequação às peculiaridades da vida rural e de cada região, especialmente:

I - conteúdos curriculares e metodologias apropriadas às reais necessidades e interesses dos alunos da zona rural;

II - organização escolar própria, incluindo adequação do calendário escolar às fases do ciclo agrícola e às condições climáticas;

III - adequação à natureza do trabalho na zona rural. (Brasil, 1996).

A referida lei aponta para uma conquista que possibilita a construção de um projeto pedagógico condizente com a realidade do homem do campo, mas a sua materialização ainda se encontra distante do que se espera para uma educação do e no campo, devido à falta de políticas públicas específicas para as atividades educacionais no campo. 
Essa lei trouxe em si "avanços" e proporcionou conquistas voltadas às políticas educacionais para o campo, mesmo que nas entrelinhas estejam os interesses neoliberais. Percebe-se certa "lapidação" de mão de obra visando o mercado de trabalho.

Segundo Arroyo (2004 p.23),

[...]. A educação do campo precisa ser uma educação específica e diferenciada, isto é, alternativa. Mas, sobretudo deve ser educação, no sentido amplo de processo de formação humana, que constrói referências culturais e políticas para intervenção das pessoas e dos sujeitos sociais na realidade, visando a uma humanidade mais plena e feliz (Arroyo, 2004, p.23).

Sendo assim, na construção de um Projeto Político Pedagógico para as Escolas do Campo é preciso que haja interação entre a escola e a família, a comunidade, e o meio sócio profissional do educando, sabendo-se que o ensino exige certas condições de aprendizagem intimamente ligadas à realidade da vida. Portanto, se faz necessário articular os saberes da vida do jovem do campo com os saberes escolares.

Neste sentido, na cidade de Luziânia-GO, em 1998, os movimentos sociais do campo articulam o movimento denominado: "Por uma Educação Básica do Campo" onde desencadeou um processo que articulou a construção de um projeto de educação do campo, o Pronera.

Posteriormente, a lei atual que rege a educação no Brasil, a Resolução CNE/CEB n 1/2002, a Resolução CNE/CEB $n^{\circ} 2 / 2008$, institui as Diretrizes Operacionais para Educação Básica das Escolas do Campo que reconhece que as escolas do campo tem uma identidade vinculada a realidade em que está inserida, e o Decreto $\mathrm{n}^{\circ}$ 7.352, de 4 de novembro de 2010, que dispõe sobre a Política Nacional de Educação do Campo e sobre o Programa Nacional de Educação na Reforma Agrária (Pronera), a partir de iniciativa MST, apoiados por entidades nacionais e internacionais, objetivando promover o acesso à educação formal em todos os níveis aos trabalhadores do campo.

O Programa Nacional de Educação na Reforma Agrária - PRONERA foi criado para atender os trabalhadores das áreas de assentamento de reforma agrária, assumido pelo governo federal, com instituições de ensino, movimentos sociais e sindicais de trabalhadores rurais, governos estaduais e municipais.

Se referindo ao Pronera, Ribeiro (2013, p.189), argumenta que "a iniciativa não parte do Estado, mas é uma resposta aos movimentos sociais populares". Nesse Decreto está contido o reconhecimento jurídico da obrigação de o Estado garantir não só a universalidade do direito à educação, mas também sua obrigatoriedade de promover intervenções que atentem às especificidades necessárias ao cumprimento e a garantia dessa universalidade.

Segundo Queiroz (2011),
Entende-se que este avanço na legislação quanto à questão específica da oferta de educação para a população rural foi o resultado da articulação dos movimentos sociais e do acúmulo das várias experiências já existentes, tais como, os Centros Familiares de Formação por Alternância, as escolas do MST, a escola ativa, as reivindicações e experiências educativas do movimento sindical, entre outras (Queiroz, 2011, p.40).

Em 2010 foi criado o Fórum Nacional de Educação do Campo - FONEC, objetivando retomar a atuação articulada de diferentes movimentos sociais, organizações sindicais, com uma participação mais ativa das universidades e institutos federais de educação.

Neste sentido, a Educação do Campo representa a luta dos trabalhadores do campo por seus direitos: civis, sociais, políticos, principalmente pela terra associado às condições dignas de vida.

Atualmente, a nomenclatura "educação rural" foi substituída pela "educação do campo" devido ao fato de que uma educação rural caracteriza-se por uma forma de educação elaborada e executada pelas classes dominantes, o grande latifúndio, atendendo aos seus interesses; já a educação do campo proporciona um redimensionamento da educação dos trabalhadores do campo onde os processos pedagógicos são pensados a partir da realidade campesina.

\section{A pedagogía da alternância}

Entende-se por Pedagogia da Alternância como sendo o diálogo entre o saber sistematizado e o saber popular, sendo o foco centrado no educando e sua realidade, buscando uma aproximação da comunidade com a escola. Essa aproximação ocorre quando a universidade vai até a comunidade, através de seus professores, e este ciclo de integração se completa quando a comunidade se desloca até a universidade, através dos alunos.

Nessa perspectiva a pedagogia da alternância tem como premissa básica a inserção da comunidade rural no cotidiano escolar. Isto significa que a instituição educacional tem como responsabilidade um fazer pedagógico interligado ao cotidiano que a circunda.

Segundo Silva (2012) “A ideia de alternancia adquire, assim, um sentido de estratégia de escolarização, que possibilita aos jovens que vivem no campo conjugar a formação escolar com as atividades e tarefas na unidade produtiva familiar, sem desvincular-se da familia e da cultura do meio rural" (Silva, 2012, p.170).

Sendo assim, a alternancia oportuniza, ao homem do campo que este aproprie dos conhecimentos adquiridos, não desconsiderando o seu conhecimento, o conhecimento popular, ou seja, o conhecimento científico e o conhecimento popular, mas asociando-os, para a construção de outros conhecimentos que produzam melhores condições de trabalho em sua comunidade.

Neste caso, os alunos não perdem o contato com suas atividades produtivas, assim como não há uma "quebra" de vínculo dos laços familiares pois o aluno retorna para o seio da família, aplicando os conteúdos estudados na 
academia, conservando assim também, suas raizes culturais.

Portanto, a alternancia ocorre quando, ao sair da escola, o aluno passa um período atuando junto à sua comunidade, e esta conexão conceitual, isto é, o diálogo dos conhecimentos escolares com os conhecimentos populares ou tradicionais modifica o campo da educação formal, posibilitando ao aluno compreender a escola como um espaço comunitário de relevância social e educacional.

De acordo com Molina (2012),

A garantia da Educação Superior em Alternância, ainda que com diferentes concepções e temporalidades variadas na execução do Tempo Escola e Tempo Comunidade, tem funcionado como estratégia relevante para a disputa de diferentes áreas do conhecimento nas quais há necessidade de formação dos trabalhadores, disputando com estas conquistas usos contra-hegemônicos dos conhecimentos adquiridos nesses cursos superiores (Molina, 2012, p, 247).

A articulação das atividades didático-pedagógicas no Tempo Escola, no caso Tempo Universidade e o Tempo Comunidade, constitui um grande desafio para os gestores educacionais considerando a quantidade de disciplinas de uma matriz curricular e sua integração com as atividades dos alunos em suas comunidades, suas unidades produtivas.

Mesmo assim, o CEB no 01/2006, do CNE, diz que a metodología recomendada para ser adotada nas escolas do campo é a Pedagogia da Alternância. Naturalmente, essa recomendação se aplica às escolas de Educação Básica.

Diante dessa recomendação do Conselho Nacional de Educação, Silva (2012, p.29) argumenta que: “Ao mesmo tempo em que a alternancia contribui para uma redefinição do ato da formação, modificando os conteúdos, ela pressupõe também uma mudança nas modalidades de transmissão desses saberes".

A pedagogia da alternância caracteriza-se também pela utilização de diversos instrumentos pedagógicos que foram surgindo ao longo de sua história, tais como: Ficha Pedagógica, Plano de Estudo, Plano de Formação ou Matriz Curricular, dentre outros.

Há de se destacar que não é a pedagogia que interfere na educação do campo, pelo menos não deveria ser, mas que se busque na pedagogia crítica os fundamentos necessários a construção de um projeto pedagógico sem tentar transformar um curso de educação do campo em curso de pedagogia, considerando que no caso em tela, as habilitações específicas são Artes Visuais e Música.

Nesse contexto, o Curso de Licenciatura em Educação do Campo, em tela, não utiliza a pedagogia da alternância, por se tratar de uma pedagogia utilizada nos Centros Familiares de Formação por Alternância CEFFAS, com suas ferramentas metodológicas.

Sendo assim, as atividades ocorrem em Regime de Alternância, distribuídas entre o Tempo Universidade e o Tempo Comunidade, e essas atividades que configuram a dimensão Tempo Comunidade, são realizadas no espaço sócio-profissional do aluno.

\section{O curso de licenciatura em educação do campo}

O processo de criação dos cursos de Licenciatura Plena em Educação do Campo faz parte de uma ação do Ministério da Educação - MEC, iniciada em 2003, que apresentava uma política nacional de educação do campo, que começou a ser formulada pela antiga Secretaria de Educação Continuada, Alfabetização e Diversidade - SECAD, que atualmente é denominada de Secretaria de Educação Continuada, Alfabetização, Diversidade e Inclusão - SECADI, políticas estas oriundas das demandas apresentadas pelos movimentos sociais campesinos.

Nesse contexto de lutas por uma educação do campo, o Ministério da Educação - MEC cria o Programa de Apoio à Formação Superior em Licenciatura em Educação do Campo - PROCAMPO, para a criação de cursos regulares para formação de profesores para as escolas do campo, os Cursos de Licenciatura em Educação do Campo.

A Universidade Federal do Tocantins-UFT/BRASIL, Campus Dr. Sérgio Jacintho Leonor, na cidade de Arraias, localizada na região sudeste do Estado de Tocantins oferece o Curso de Licenciatura em Educação do Campo com Habilitações em Artes Visuais e Música, contando em 2017 com 319 alunos matriculados, atualmente distribuidos em 7 turmas.

O curso iniciou suas atividades didático-pedagógicas no ano de 2014, em regime de alternância, ou seja, as atividades desenvolvidas no Tempo Universidade (TU) e o Tempo Comunidade (TC), quando os alunos retornam para as suas comunidades para aplicar os conteúdos vivenciados no Tempo Universidade. Nesse trânsito, a partir de sua comunidade, o aluno observa e descreve a realidade de seu contexto sócio-profissional, vai para a universidade onde socializa, analisa, reflete, sistematiza e interpreta os conteúdos identificados e depois volta para sua realidade, com os conteúdos trabalhados, no intuito de transformar a sua realidade.

As atividades didático-pedagógicas do curso, no Tempo Universidade, ocorrem nos meses de janeiro e julho de cada ano, em tempo integral, e as atividades do Tempo Comunidade ocorrem aos sábados e domingos nas comunidades integradoras, para onde os professores se deslocam para a realização das atividades.

Para a realização da alternância, os alunos foram agrupados em 4 comunidades integradoras, a saber: $1^{\mathrm{a}}=$ Arraias-TO, seu municipio e seus distritos; $2^{\mathrm{a}}=$ Paranã-TO, é composta do seu municipio, seus distritos e outros municipios adjacentes; Taguatinga-TO, é composta por seu municipio, seus distritos e municipios adjacentes, onde os alunos estão distribuidos, em um raio de $300 \mathrm{KM}$ aproximadamente.

Com esta formatação, de acordó com o Projeto Pedagógico do Curso - PPC (2013), o objetivo do curso é "formar um profissional capaz de: (i) exercer a docência multidisciplinar, a partir da área de conhecimento propostas, a saber: Códigos e Linguagens; (ii) participar da gestão de processos educativos escolares; (iii) ter 
atuação pedagógica nas comunidades rurais, para além da prática escolar" (PPC, 2013, p.33).

Pretende-se formar um profissional para atuar nas escolas do campo, nos anos finais do Ensino Fundamental e no Ensino Médio, que domine 2 linguagens artísticas: Artes Visuais e Música, idéia de polivalência já vivenciada na educação brasileira quando da vigência da Lei 5.692/71, onde a extinta Educação Artística pretendia formar o professor polivalente que dominasse 3 áreas do conhecimento: Artes Plásticas, Teatro e Música.

De acordo com o PPC (2013), no que diz respeito ao perfil profissiográfico do egresso, destaca-se duas questões: A primeira é que ele está estruturado de forma que o aluno "tem uma sólida formação de base generalista, crítica e ética, possibilitando ao cidadão-profissional aprofundamento em áreas de conhecimento do Curso". Discutindo esta questão problematiza-se: Como garantir um aprofundamento em 2 áreas distintas do conhecimento, com a falta de disciplinas indispensáveis à formação do educador musical e uma carga horária insuficiente? Isso associado à falta de conhecimentos musicais em nível de ensino médio. A segunda questão quanto ao perfil profissiográfico abordado no PPC é que o egresso "conheça as novas tecnologias e que as utilize, de acordo com o projeto político de emancipação das classes menos privilegiadas". Nova problematização se faz necessária: Como conhecer as novas tecnologias se na matriz curricular não contém disciplinas voltadas para o estudo das tecnologias? (PPC, 2013, p.34).

O ementário e a bibliografia necessitam de uma maior atenção, considerando que muitos dos conteúdos específicos das ementas estão voltados para um nível de bacharelado e a bibliografia não contempla títulos essenciais e indispensáveis à formação do educador musical na contemporaneidade.

Diante do exposto, o Núcleo Docente Estruturante-NDE, órgão consultivo no âmbito do curso, tem produzido as mudanças e correções necessárias para que os objetivos propostos possam ser melhor alcançados. Esta reestruturação do Projeto Pedagógico do Curso será encaminhada ao colegiado do curso para aprovação, e encaminhado às demais instâncias institucionais.

\section{Educação musical no campo}

A Educação Musical consiste basicamente em desenvolver no indivíduo a percepção musical, a criatividade e a sensibilidade musical. Assim, ele poderá reconhecer o material sonoro/musical como parte integrante do fazer musical na prática docente.

Penna (2010) defende uma educação musical que contribua para a expansão - em alcance e qualidade - da experiência artística e cultural de nossos alunos, cabe adotar uma concepção ampla de música e de arte que, suplantando a oposição entre popular e erudito, procure apreender todas as manifestações musicais como significativas - evitando, portanto, deslegitimar a música do outro, através da imposição de uma única visão (Penna, 2010, p.93).
Entende-se que ultimamente, o campo não é visto somente como um espaço de produção agrícola e de lutas por terras, mas um pólo gerador de cultura, de conhecimento popular e de valorização do ser humano. Sendo assim, o homem do campo não pode ser privado do acesso aos bens culturais da humanidade, no caso em estudo, a música.

Neste sentido, para Carvalho (2016), “O campo é um espaço rico e diverso, que tem suas particularidades e ao mesmo tempo é produto e produtor de cultura. É essa capacidade produtora de cultura que o constitui em espaço de criação do novo e do criativo. É um espaço emancipatório, um território fecundo de construção da democracia e da solidariedade, ao transformar-se no lugar não apenas das lutas pelo direito a terra, mas, também, pelo direito a educação" (Carvalho, 2016, p.140).

Neste contexto, se encontra a educação nas escolas do campo que é vista por muitos como uma educação diferente e diferenciada entre o homem do campo e o homem das grandes cidades, a ponto de se elaborar metodologias e conteúdos mais acessíveis à compreensão deste homem.

Para Santos e Almeida (2012, p.144), “A escola do campo não pode ser um modelo distorcido da escola da cidade, ou um modelo menor quanto aos processos educacionais discutidos pela teoria pedagógica".

Corroborando com os autores, a partir de um melhor conhecimento da realidade do campo, no que diz respeito a educação e cultura campesina, o professor de música da disciplina Voz I e II, a partir do contato direto com a realidade do campo entende que o homem campesino está em igualdade de condições em relação ao homem das grandes metrópoles, no sentido de estar apto para o aprendizado da música, até mesmo utilizando as diversas tecnologias. Se na academia o homem do campo estuda Platão, Kant, Aristóteles, Sócrates, Descartes, Nietzsche, Marx, Durkheim, Weber, dentre outros, sem dúvida estará apto para estudar música.

O que difere o curso educação do campo e as escolas do campo em relação aos cursos de música das cidades é o regime de alternância que requer práticas pedagógicas voltadas à realidade campesina.

Sobre essa realidade, Silva (2016) argumenta que:

Nesse contexto educacional necessário se faz portanto refletir para discutir as práticas pedagógico-musicais específicas para esses povos levando-se em consideração o regime de alternância, buscando uma conexão com a realidade dos camponeses, assim como também reflexões de caráter interdisciplinar que estejam em consonância com os novos paradigmas educacionais (Silva, 2016, p.7).

Ainda sobre as práticas pedagógico-musicais utilizadas na educação do campo, Silva (2016) acrescenta dizendo: As práticas pedagógico-musicais desenvolvidas buscam ressignificar a vida, cultura, trabalho e a dignidade dos sujeitos do campo, envolvidos no processo educacional, mesmo considerando que no caso especifico das comunidades envolvidas, via de regra, o campo já não é mais visto por 
algumas pessoas como um espaço de subdesenvolvimento (Silva, 2016, p.7).

Diante dessas reflexões, as atividades teórico-práticas desenvolvidas nas disciplinas específicas para a educação musical dos sujeitos ocorreram no Tempo Universidade e, neste ensaio, será enfatizada a disciplina Voz I e II, que em outras universidades recebe o nome de Canto Coral ou Prática Coral.

As dificuldades enfrentadas para uma formação consistente de um docente em música para atuar nas escolas do campo estão relacionadas à falta de disciplinas indispensáveis, a inexistência de disciplinas de música no segundo semestre do curso e uma carga horária específica de música reduzida, $600 \mathrm{~h} / \mathrm{a}$ distribuídas para as disciplinas de música, considerando que a carga horária do curso é de $3.300 \mathrm{~h} / \mathrm{a}$.

Associa-se a essas dificuldades, o regime de alternância adotado pelo curso, em que os alunos ficam meses sem contato direto com a música, de forma presencial, acompanhados pelo professor, mesmo tendo estes alunos, adquirido seus instrumentos musicais.

Diante dessas e outras dificuldades, metodologias alternativas foram utilizadas para a transmissão de conteúdos, como uma alternativa para tentar corrigir as fragilidades apresentadas pelo projeto pedagógico do curso.

A internet e, mais especificamente o whatsapp foram utilizados para a gravação e envio de áudio e vídeo do repertório estudado no Tempo Universidade, para estudo no Tempo Comunidade, com a devolutiva em áudio e/ou vídeo das tarefas executadas pelos alunos nesse período, para análise e avaliação do professor.

A metodologia constou do estudo e aprendizado tradicional de um repertório de música folclórica e popular brasileira. Dentre as metodologias utilizadas para que se alcancem os objetivos propostos, destaca-se a percussão corporal, a partir das ideias de Émile-Jaques Dalcroze (1865-1950), com o ensino de música baseado no movimento e percussão corporal, e a associação da voz, corpo e movimento, utilizadas como recurso didático-pedagógico no processo de ensino e aprendizagem da música. Já dizia Dalcroze: "Não ouvimos a música só com os nossos ouvidos, ela ressoa no corpo inteiro, no cérebro e no coração".

Destaca-se também a utilização das tecnologias, com muito boa aceitação por parte dos alunos, despertando maior interesse para o estudo da música. A percussão corporal aplicada e incorporada ao processo de educação musical, associado à utilização de instrumentos de percussão tocado pelos alunos produziu considerável desenvolvimento técnico-musical. Os instrumentos de percussão executados por um grupo de instrumentistas para acompanhar as músicas produziu um efeito estético-visual-auditivo perceptível e agradável, conforme manifestação do público presente e depoimento dos alunos.

\section{Considerações finais}

Os estudos demonstram que a educação do campo carece de mais políticas públicas que venham consolidar e garantir uma educação igualitária de qualidade para o homem co campo.

O Curso de Educação do Campo da Universidade Federal do Tocantins precisa reestruturar o seu Projeto Pedagógico no sentido de garantir uma formação docente que atenda as 2 habilitações oferecidas, sabendo-se que na literatura específica, a polivalência já foi discutida e se concluiu que a fornação em mais de uma área do conhecimento, no mesmo curso, compromete a qualidade do ensino.

As práticas pedagógicas utilizadas, mesmo com as metodologias alternativas, demonstraram que o regime de alternância não é a pedagogia adequada para um curso de gradução que oferece 2 habilitações. Entende-se que, para melhor compreensão e aplicação dos conteúdos, as atividades precisam ser semanais e presenciais, como nos cursos regulares.

\section{Referências}

Arroyo, Miguel Gonzalez (2004). Imagens quebradas. Petrópolis: Vozes.

Brasil (2002). CNE/CEB No 01/2002- Diretrizes Operacionais da Educação Básica para as Escolas do Campo. Brasília.

Brasil (2010). Presidência da República. Decreto $n^{\circ}$ 7.352, de 4 de novembro de 2010. Dispõe sobre a Política Nacional de Educação do Campo e sobre o Programa Nacional de Educação na Reforma Agrária. DOU, Brasília.

Carvalho, Raquel Alves de (2016). Identidade e Cultura dos povos do campo no Brasil: entre preconceitos e resistências, qual o papel da educação? Curitiba: Appris.

Caldart, Roseli Salete (2009). Educação do Campo: notas para uma análise de percurso. Trab. Educ. Saúde. Rio de Janeiro.

Molina, Mônica Castagna (2012). Educação do Campo: novas práticas construindo novos territórios. In. Territórios educativos na educação do campo: escola, comunidade e movimentos sociais. Belo Horizonte: Autêntica Editora.

Penna, Maura (2010). Música(s) e seu ensino. 2. ed. Porto Alegre: Sulina.

Universidade Federal do Tocantins - UFT. Projeto Pedagógico do Curso de Licenciatura em Educação do Campo - PPC (2013). Universidade Federal do Tocantins. Arraias-TO/BR.

Queiroz, João Batista Pereira de (2011). A educação do campo no Brasil e a construção das escolas do campo. In. Revista Nera. Ano 14. no 18. Presidente Prudente.

Ribeiro, Marlene (2013). Movimento camponês, trabalho e educação: liberdade, autonomia, emancipação: princípios/fins da formação humana. 2 ed. São Paulo: Expressão Popular.

Santos, Ademar Vieira dos; Almeida, Luis Sérgio Castro de (2012). Perspectivas curriculares para a educação no campo: algumas aproximações para a construção do currículo da escola dos que vivem no e do campo. In. 
Educação do campo: epistemologia e práticas. Evandro Ghedin (Org). São Paulo: Cortez.

Silva, Lourdes Helena da (2012). As experiências de formação de jovens do campo: alternância ou alternâncias? Curitiba, PR: CRV.

Silva, W.P. (2016). O ensino de música no Curso de Licenciatura em Educação do Campo no Campus de Arraias-TO: relato de experiência. In. I Seminário Internacional de Educação do Campo. Uberlândia. 